\title{
ADSORÇÃO DE ÁCIDOS GRAXOS LIVRES PRESENTES EM BIOCOMBUSTÍVEIS GERADOS POR CRAQUEAMENTO TERMOCATALÍTICO EMPREGANDO ALUMINA ATIVADA COMO ADSORVENTE
}

\author{
K. M. B. da $\operatorname{COSTA}^{1}$, A. A. MANCIO ${ }^{2}$, E. S. PAMPOLHA Jr ${ }^{3}$, M. E. C. $\operatorname{CORDEIRO}^{3}$ e N. T. \\ MACHADO $^{4}$
}

${ }^{1}$ Universidade Federal do Pará, Discente do Programa de Pós-Graduação em Engenharia Química (PPGEQ)

${ }^{2}$ Universidade Federal do Pará, Discente do Programa de Pós-Graduação em Engenharia de Recursos Naturais da Amazônia (PRODERNA)

${ }^{3}$ Universidade Federal do Pará, Discente da Faculdade de Engenharia Química

${ }^{4}$ Universidade Federal do Pará, Docente da Faculdade de Engenharia Química

E-mail para contato: karen.costa@live.com

RESUMO - A cinética de adsorção de ácidos graxos livres (ácidos carboxílicos) residuais presentes em frações destiladas (faixa de temperatura de ebulição de 305$400^{\circ} \mathrm{C}$ ) provenientes do Produto Líquido Orgânico (PLO) obtido por craqueamento termocatalítico de óleo vegetal foi investigada pela determinação da variação da concentração de ácidos graxos livres nos biocombustíveis antes e depois dos experimentos de adsorção com $5 \%$ de alumina ativada termicamente. A capacidade da alumina ativada como adsorvente em relação à adsorção de ácidos graxos livres foi avaliada através de estudos cinéticos em sistema de batelada à temperatura de $26^{\circ} \mathrm{C}$ (temperatura ambiente). Os resultados experimentais indicam que a concentração de ácidos graxos livres presentes em quatro frações destiladas (biocombustíveis) foi reduzida após a adsorção com 5\% em massa de alumina ativada, sendo que o melhor resultado foi alcançado para a alimentação com menor teor de AGLs residuais, em que $69,03 \%$ dos ácidos graxos livres foram removidos da referida alimentação. Apesar de ter sido observado que a taxa inicial de adsorção aumenta com o incremento de AGLs na alimentação, quanto maior o teor de AGL na alimentação, menor o efeito da remoção de AGLs em relação à quantidade inicial. Portanto, os resultados mostraram que a alumina ativada termicamente na proporção usada neste trabalho é um adsorvente promissor na remoção dos ácidos graxos livres e que o teor de AGLs tem efeito direto sobre o desempenho da adsorção dos mesmos.

\section{INTRODUÇÃO}

O interesse por combustíveis obtidos a partir de fontes renováveis tem crescido nos últimos anos, buscando principalmente a diminuição dos níveis de emissões gasosas causadas, sobretudo, por 


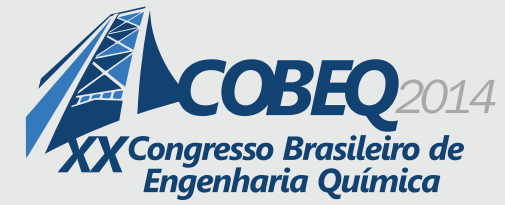

19 a 22 de outubro de 2014

Florianópolis/SC

combustíveis fósseis. A maior conscientização dos países na busca por combustíveis alternativos que minimizem a emissão de poluentes tem contribuído para que sejam desenvolvidos combustíveis a partir de biomassa, fazendo com que a demanda por tecnologia nessa área cresça rapidamente (HAAS et al., 2001).

O processo de craqueamento termocatalítico dos óleos vegetais ocorre em temperaturas acima de $350^{\circ} \mathrm{C}$. Durante o processo, ocorre a quebra das moléculas dos triglicerídeos, que são os principais constituintes dos óleos vegetais, levando à formação do Produto Líquido Orgânico (PLO), o qual é uma mistura de hidrocarbonetos e compostos oxigenados, tais como alcanos, alcenos, cetonas, ácidos carboxílicos e aldeídos (SUAREZ et al., 2007).

Um dos problemas da aplicação direta do PLO é a elevada acidez que estes produtos apresentam, onde o principal responsável por essa acidez são os ácidos graxos livres (AGL) presentes no produto obtido. Vários processos podem ser empregados com o objetivo de diminuir essa acidez, entre eles o processo de adsorção (HANN, 2008).

Adsorção é uma operação de transferência de massa do tipo sólido fluido na qual se explora a habilidade de certos sólidos em concentrar na sua superfície determinadas substâncias existentes em soluções liquidas ou gasosas, o que permite separá-las dos demais componentes dessas soluções (GOMIDE, 1987). O processo de adsorção depende muito do sólido que será utilizado como adsorvente, que deve apresentar principalmente uma alta área específica, diâmetro e número de poros. Os principais adsorventes empregados na adsorção são o carvão ativado, sílica, sílica-alumina, alumina e argila ativada (RUTHVEN, 1984).

A alumina sem tratamento não apresenta as características necessárias para um bom adsorvente. Porém, quando ativada termicamente apresenta um aumento no número de poros e área superficial específica, o que favorece o seu desempenho no processo de adsorção (OLIVEIRA, 2005). O aumento da área superficial do adsorvente alumina obtido por meio da ativação térmica ocorre devido à remoção das hidroxilas sob a forma de moléculas de água, presentes no Hidróxido de Alumínio (AMARAL, 2013).

Assim, o presente trabalho teve por objetivo principal avaliar o efeito da concentração inicial de ácidos graxos livres presente na alimentação (frações destiladas na faixa de temperatura de $305-400^{\circ} \mathrm{C}$ proveniente do produto líquido orgânico produzido por craqueamento térmico-catalítico do óleo de palma) sobre o processo de adsorção, empregando alumina ativada termicamente como adsorvente.

\section{MATERIAIS E MÉTODOS}

\subsection{Adsorvente}

$\mathrm{O}$ adsorvente empregado no presente trabalho foi alumina ativada, a qual foi obtida a partir de Hidróxido de Alumínio [Al $(\mathrm{OH})_{3}$ ], material cedido pela empresa ALUNORTE S/A (Barcarena-ParáBrasil). Baseado no método descrito por Cunha et al. (2012), inicialmente, as amostras de Hidróxido de Alumínio $\left[\mathrm{Al}(\mathrm{OH})_{3}\right]$, o precursor do adsorvente, foram lavadas em água a aproximadamente 


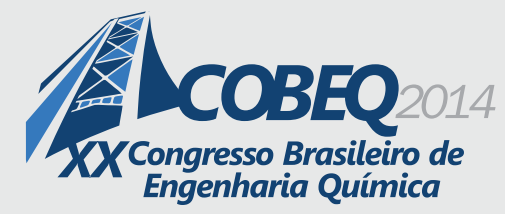

19 a 22 de outubro de 2014

Florianópolis/SC

$100^{\circ} \mathrm{C}$, sob agitação em béquer de $600 \mathrm{ml}$, durante 60 minutos, objetivando-se remover o teor de hidróxido de sódio residual e outras impurezas indesejáveis. Em seguida, as amostras de Hidróxido de Alumínio $\left[\mathrm{Al}(\mathrm{OH})_{3}\right]$ úmidas foram submetidas a secagem a $105^{\circ} \mathrm{C}$, por um período de 24 horas, em estufa de recirculação de ar. Após o período de secagem as amostras de Hidróxido de Alumínio $\left[\mathrm{Al}(\mathrm{OH})_{3}\right]$, foram submetidas ao tratamento térmico. O processo foi realizado à temperatura de $450^{\circ} \mathrm{C}$ em forno elétrico, com controle digital de temperatura, rampa e taxa de aquecimento $\left(5^{\circ} \mathrm{C} / \mathrm{min}\right)$, durante 120 minutos.

\subsection{Fração destilada}

As frações destiladas usadas neste trabalho e adotadas como alimentação foram obtidas no Laboratório de Processos de Separações Térmicas (THERMTEK/FEQ/ITEC/UFPA) através da destilação a pressão atmosférica (coluna de destilação piloto) do Produto Líquido Orgânico produzido por craqueamento termocatalítico do óleo de palma. Para o desenvolvimento do presente estudo foram selecionadas quatro frações destiladas na faixa de temperatura de 305$400^{\circ} \mathrm{C}$, as quais cada uma das frações apresentava um teor de ácido graxo livre diferente, conforme apresentado na Tabela 1, com o objetivo de avaliar o efeito do teor de ácido graxo livre inicial (da alimentação) sobre a adsorção dos mesmos.

Tabela 1 - Frações destiladas na faixa de temperatura de $305-400^{\circ} \mathrm{C}$ destinadas a desacidificação por adsorção

\begin{tabular}{cc}
\hline Alimentação & NAT (mg KOH/g) \\
\hline A & 1,5547 \\
B & 19,6470 \\
C & 24,4802 \\
D & 77,3601 \\
\hline
\end{tabular}

\subsection{Cinética de adsorção de ácidos graxos livres}

Os experimentos de cinética de adsorção dos ácidos graxos livres foram realizados no sistema de batelada em frascos erlenmeyer de $250 \mathrm{~mL}$, os quais foram dispostos em uma mesa agitadora (AGIF/RES-MCT-010/Ética/Q-842-210) com agitação orbital para que as frações destiladas tivessem o contato adequado com o adsorvente. Cinco gramas de fração destilada e 5\% de adsorvente (alumina ativada termicamente) foram adicionados em cada erlenmeyer e, em seguida, agitou-se por tempos pré-estabelecidos.

As condições experimentais mantidas constantes foram temperatura ambiente, pressão atmosférica, velocidade de agitação de $160 \mathrm{rpm}$, porcentagem de adsorvente (5\%), variando apenas o teor de ácidos graxos livres iniciais (número de ácidos totais da alimentação) e o tempo de contato $(0 ; 2,5 ; 5 ; 10 ; 20 ; 30 ; 40 ; 50 ;$ e 60$)$ a fim de se obter cinéticas de adsorção. Após o procedimento de adsorção, o conteúdo do frasco foi submetido à filtração a vácuo, empregando papel filtro Whatman $\mathrm{n}^{\circ} 1$, obtendo-se como parte filtrada uma fração destilada desacidificada, a qual foi determinada o número de ácidos totais de acordo com o método padrão da ASTM D 974. 


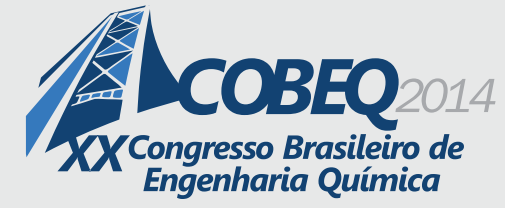

A avaliação da quantidade relativa de ácidos graxos livres removidos foi realizada através e titulação colorimétrica, em que foi utilizado o método padrão da ASTM D 974 para determinar o número de ácidos totais (NAT) antes e depois da adsorção.

\section{RESULTADOS E DISCUSSÃO}

As Tabelas 2 e 3 apresentam os resultados da cinética de adsorção dos ácidos graxos livres. Os resultados apresentados estão relacionados à quantidade relativa de ácidos graxos livres adsorvidos nos diferentes tempos de contato dos experimentos feitos com quatro alimentações (frações destiladas na faixa de temperatura de $305-400^{\circ} \mathrm{C}$ ) distintas em relação ao teor de ácidos graxos livres, onde através destes resultados podemos verificar a desempenho do adsorvente.

Tabela 2 - Quantidade relativa de ácidos graxos livres residuais em função do tempo de contato das frações destiladas na faixa de temperatura de $305-400^{\circ} \mathrm{C}$

\begin{tabular}{ccccc}
\hline \multirow{2}{*}{$\begin{array}{c}\text { Tempo de Contato } \\
\text { (min) }\end{array}$} & A & B & C R Residual (\%) & D \\
\cline { 2 - 5 } & 100 & 100 & 100 & 100 \\
2,5 & 92,95 & 76,1404 & 80,6166 & 96,6861 \\
5 & 43,93 & 74,8389 & 84,7983 & 94,9179 \\
10 & 40,40 & 74,3360 & 79,7379 & 94,9152 \\
20 & 31,74 & 75,9999 & 84,1353 & 94,1290 \\
30 & 35,10 & 71,3208 & 80,4132 & \\
40 & 30,97 & 74,9626 & 80,9401 & 95,3463 \\
50 & 38,39 & 73,4840 & 79,7020 & 94,3718 \\
60 & 32,89 & 71,0246 & 79,1252 & 94,9206 \\
\hline Alimentação: $\mathrm{A}=1,5547 \mathrm{mg} \mathrm{KOH} / \mathrm{g} ; \mathrm{B}=19,6470 \mathrm{mg} \mathrm{KOH} / \mathrm{g} ; \mathrm{C}=24,4802$ & $\mathrm{mg} \mathrm{KOH} / \mathrm{g} ; \mathrm{D}=77,3601 \mathrm{mg} \mathrm{KOH} / \mathrm{g}$.
\end{tabular}

A partir dos resultados mostrados na Tabela 2, observou-se para a cinética de adsorção da alimentação $\mathrm{A}$, que quando aumentamos o tempo de contato do adsorvente com a alimentação a porcentagem de ácidos graxos livres residuais diminuiu. Apesar de observarmos que a partir de 5 minutos de tempo de contato o adsorvente consegue remover mais de $50 \%$ de AGL, a menor porcentagem de AGL residuais foi alcançado em 40 minutos de contato da alumina ativada com a alimentação A, em que permaneceram apenas 30,97\% de AGL após a adsorção, ou seja, 69,03\% dos ácidos graxos livres foram removidos da referida alimentação.

Quando comparamos a porcentagem de AGLs residuais da alimentação A com os AGLs residuais da alimentação $\mathrm{B}, \mathrm{C}$ e $\mathrm{D}$, foi possível observar através da Tabela 2 que a alumina, na proporção de $5 \%$ em massa em relação a massa da alimentação, conseguiu retirar mais do que a metade dos ácidos graxos livres presente na alimentação $\mathrm{A}$, enquanto que a quantidade de ácidos graxos livres removidos na alimentação $\mathrm{B}, \mathrm{C}$ e $\mathrm{D}$ não alcançaram $30 \%$ em relação a quantidade inicial, permanecendo ainda uma quantidade significativa de ácidos residuais nas frações destiladas após a adsorção. 
Tabela 3 - Quantidade relativa de ácidos graxos livres adsorvidos em função do tempo de contato das frações destiladas na faixa de temperatura de $305-400^{\circ} \mathrm{C}$

\begin{tabular}{ccccc}
\hline \multirow{2}{*}{$\begin{array}{c}\text { Tempo de } \\
\text { contato }(\mathrm{min})\end{array}$} & \multicolumn{4}{c}{ mg AGL adsorvidos/g adsorvente } \\
\cline { 2 - 5 } & $\mathrm{A}$ & $\mathrm{B}$ & $\mathrm{C}$ & $\mathrm{D}$ \\
\hline 0 & 0,0000 & 0,0000 & 0,0000 & 0,0000 \\
2,5 & 0,4384 & 18,4193 & 18,9123 & 10,2258 \\
5 & 3,4872 & 19,6791 & 14,8263 & 15,6136 \\
10 & 3,6766 & 20,0405 & 19,7303 & 15,6343 \\
20 & 4,2452 & 18,8236 & 15,4483 & 18,1382 \\
30 & 4,0356 & 22,4576 & 19,0728 & 15,0149 \\
40 & 4,2928 & 19,6215 & 18,4132 & 14,3774 \\
50 & 3,8308 & 20,5426 & 19,8047 & 16,9945 \\
60 & 4,1570 & 22,6895 & 19,5718 & 15,4701 \\
\hline
\end{tabular}

Alimentação: A = 1,5547 mg KOH/g; B = 19,6470 mg KOH/g; C = 24,4802 mg KOH/g; D = 77,3601 mg KOH/g.

A Figura 1 apresenta, na forma de gráfico, a quantidade relativa de ácidos graxos livres adsorvidos, os mesmos dispostos na Tabela 3, para a cinética de adsorção das quatro frações destiladas.

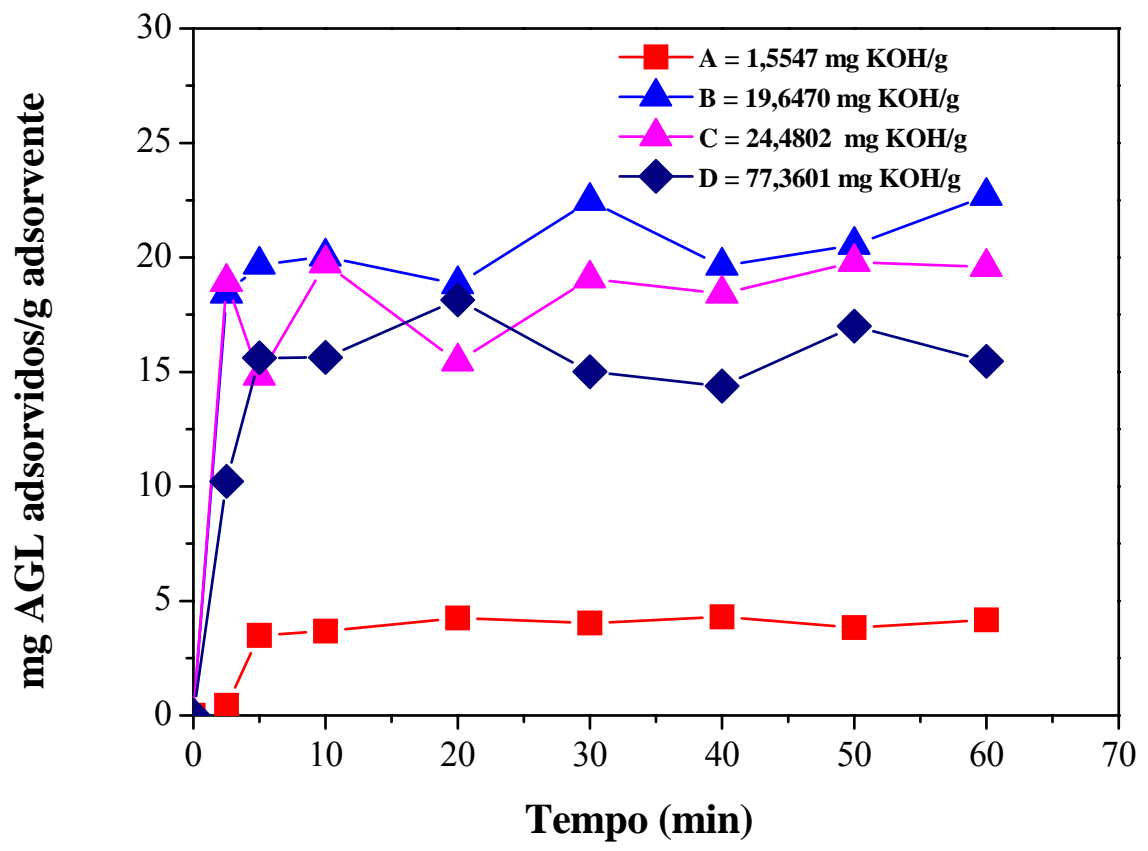

Figura 1 - Cinética de adsorção de ácidos graxos livres residuais com 5\% de alumina ativada.

A partir dos resultados obtidos, observa-se através da Figura 1 que a quantidade relativa de AGLs adsorvidos aumenta com o tempo, alcançando uma quantidade máxima nas cinéticas de 


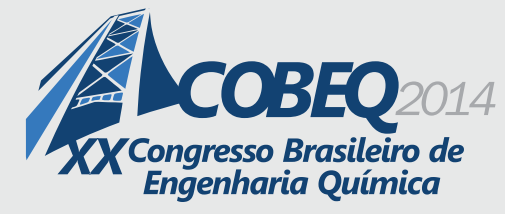

adsorção, e depois de um determinado tempo de contato verifica-se que a quantidade relativa de AGLs adsorvidos se mantém praticamente constante para a alimentação $\mathrm{A}$, indicando que o equilíbrio de adsorção foi alcançado. Assim, o tempo de contato necessário para alcançar o equilíbrio de adsorção dos AGLs presentes nas frações destiladas foi de 10 min para a alimentação A. Para as alimentações B, $\mathrm{C}$ e D, não foi possível observar o tempo de contato necessário para alcançar o equilíbrio de adsorção em função da oscilação dos valores obtidos na cinética das mesmas. Isso indica que a alimentação $\mathrm{B}, \mathrm{C}$ e D necessitam de um tempo de contato superior ao investigado no presente trabalho para alcançar o equilíbrio de adsorção.

A partir dos resultados apresentados na Figura 1 para as alimentações A e B, observou-se que o um incremento no teor de AGL aumentou a taxa inicial de adsorção dos ácidos graxos livres presentes nas frações destiladas. Este fato, isto é, o aumento da taxa inicial de adsorção com a elevação da concentração inicial também foi constatado por Silva (2010) em seu trabalho de adsorção de ácidos orgânicos passíveis de produção por via fermentativa e de relevância em petroquímica verde, empregando carvão ativado e resinas poliméricas como adsorventes e, por Lin e Lin (2005) que investigaram a cinética de adsorção de ácidos AGL residuais a partir de óleo de soja degomado com água e óleo de soja refinado com uma base, empregando argila regenerada.

O mesmo não foi observado quando se compara o teor de AGL da alimentação B com o teor de AGL das alimentações $\mathrm{C}$ e $\mathrm{D}$, em que o incremento no teor de ácidos graxos livres favoreceu uma redução na taxa inicial de adsorção. Estes últimos resultados estão em discordância com a literatura, a qual relata que, normalmente, quanto maior a concentração inicial do soluto, maior é a velocidade de adsorção, como foi constatado por Silva (2010). Além disso, tem-se que apesar da taxa inicial de adsorção aumentar com o aumento do teor de ácidos graxos livres presentes nas frações destiladas (Figura 1), quanto maior o teor de ácidos da alimentação menor é o efeito de adsorção por parte da alumina ativada em relação à quantidade inicial de ácidos (Tabela 2).

\section{CONCLUSÃO}

O presente trabalho apresentou a cinética de adsorção dos ácidos graxos livres presentes em frações destiladas na faixa de temperatura de $305-400^{\circ} \mathrm{C}$ com diferentes teores de AGL, utilizando $5 \%$ de alumina ativada termicamente. Os melhores resultados foram alcançados com 40 minutos de contato da alumina ativada com a alimentação A, em que $69,03 \%$ dos ácidos graxos livres foram removidos da referida alimentação. A quantidade de ácidos graxos livres removidos nas alimentações $\mathrm{B}, \mathrm{C}$ e $\mathrm{D}$ não alcançaram $30 \%$ em relação à quantidade inicial, permanecendo ainda uma quantidade significativa de ácidos residuais nas frações destiladas após a adsorção. Em relação à cinética de adsorção, o tempo de contato necessário para alcançar o equilíbrio de adsorção dos AGLs presentes nas frações destiladas foi de 10 min para a alimentação A. Para as alimentações $\mathrm{B}, \mathrm{C}$ e $\mathrm{D}$, não foi possível observar o tempo de contato necessário para alcançar o equilíbrio de adsorção, indicando que essas alimentações necessitam de um tempo de contato superior ao investigado no presente trabalho para alcançar o equilíbrio de adsorção. Portanto, concluiu-se ao final do presente trabalho que o teor de AGLs tem efeito direto sobre o desempenho da adsorção dos mesmos e que a alumina é um adsorvente promissor no que se refere à adsorção de ácidos graxos livres que constituem frações destiladas na faixa de temperatura de $305-400^{\circ} \mathrm{C}$ provenientes do produto líquido orgânico gerado por craqueamento térmico catalítico de óleo de vegetal. 


\section{REFERÊNCIAS}

AMARAL, A. R. Estudo Cinético e das Isotermas de Adsorção dos Óleos de Palma (Elaies guineenses, Jacq.) e Andiroba (Carapa guianensis, Aubl.) em $\gamma$-Alumina e Modelagem da Dessorção com Dióxido de Carbono Supercrítico. 2013. 145 f. Dissertação (Mestrado em Engenharia Química). Universidade Federal do Pará, Belém, 2013.

CUNHA, M. A. E.; NEVES, R. F.; SOUZA, J. N. S.; FRANÇA, L. F.; ARAUJO, M. E.; BRUNNER, G.; MACHADO, N. T. Supercritical adsorption of buriti oil ( mauritia flexuosa mart.) in $\gamma$-alumina: a methodology for the enriching of anti-oxidants. Journal of Supercritical Fluids. V. 66, pag 181-191, 2012.

GOMIDE, R. Operações unitárias: operações de transferência de massa. $1^{\mathrm{a}}$ ed. São Paulo: Dag Gráfica e Editora ltda., 1988 v. 4.

HAAS, M. J.; SCOTT, K. M.; ALLEMAN, T. L.; MCCORMICK, R. L. Engine Performance of Biodiesel Fuel Prepared from Soybean Soapstok a High Quality Renewable Fuel Produced from a Waste Feedstock. Energy Fuels 2001, 15 (5), 1207.

HANN, C. J. The Adsorption Of Fatty Acids Using Metal Silica Complexes From Rice Husk Ash. 2008. Tese de Mestrado. Universiti Sains Malaysia, 2008.

LIN, H. R., LIN, C. I. Kinetics of adsorption of free fatty acids from water-degummed and alkalirefined soy oil using regenerated Clay. Separation and Purification Technology. V. 44, pag. 258-265, 2005 .

OLIVEIRA, L. B.; ANGÉLICA, R. S.; NEVES, R. F.; FIGUEIREDO, B.R. Avaliação da Adsorção do Íon $\mathrm{As}(\mathrm{V})$ em Solução sobre Alumina Ativada, Rejeitos de Caulim e seus Produtos de Transformação. Workshop Internacional em Geologia Médica, 2005.

RUTHVEN, D. M. Principles of adsorption and adsorption process. United States of America: Wiley - Interscience Publication, 1984 p. 1 - 13, 221 - 270.

SILVA, A. H. Estudos de adsorção de ácidos orgânicos visando sua recuperação de meios fermentados. 2010. 134 f. Dissertação. (Mestrado em Engenharia Química) Universidade Estadual de Campinas, Campinas, 2010.

SUAREZ, P. A. Z.; MENEGHETTI. S. M. P.; MENEGHETTI. M. R.; WOLF. C. R. Transformação de Triglicerídeos em Combustíveis, Materiais Poliméricos e Insumos Químicos: Algumas Aplicações da Catálise na Oleoquímica. Química Nova. V. 30, No. 3, p. 667-676, 2007. 